\title{
Compartilhando universos sociais e de poder em Cerimônia do chá
}

Sharing Social and Power Universes in Cerimônia do chá

\author{
Maria Luci De Biaji Moreira* \\ College of Charleston \\ Charleston - Carolina do Sul / Estados Unidos \\ Mércia Regina Santana Flannery** \\ University of Pennsylvania \\ Filadélfia - Pensilvânia / Estados Unidos
}

Resumo

Este estudo compreende uma análise do conto Cerimônia do chá, de Maria Telles Ribeiro, baseada tanto em princípios da pragmática aplicados ao texto literário como na análise da narrativa e do discurso. O objetivo deste estudo é propor, com base na análise linguística do conto, uma explicação para a razão por que leitores de português - como língua estrangeira ou não - podem experienciar dificuldades de compreendê-lo.

Palavras-chave

Análise do discurso; conto; narrativa oral; leitor; relações de classe e poder.

\section{Abstract}

This paper presents an analysis of Cerimônia do chá, a short story by Maria Telles Ribeiro. The study is based both on pragmatic principles

\footnotetext{
*moreiral@cofc.edu

** merciaf@sas.upenn.edu
} 
applied to the literary text, as in narrative and discourse analysis. The objective of this study is to propose, based on a linguistic analysis of the short story, an explanation as to why readers of Portuguese - as a foreign language or not — may experience difficulty to understand it.

\section{Keywords}

Discourse analysis; short story; oral narrative; reader; power and class relations. 


\section{INTRODUÇÃO}

motivação inicial para analisar o texto Cerimônia do chál deve-se à experiência
de o termos usado como material didático para estudantes de Português
como Língua Estrangeira $(\mathrm{L} 2 / \mathrm{LE})^{2}$ tanto no College of Charleston (SC) como na University of Pennsylvania (PA). Esse texto literário, empregado como ferramenta de ensino, remeteu-nos a elementos culturais e a um discurso escrito com características de texto oral, que nos levaram a refletir sobre seu uso em sala de aula.

O emprego de termos e expressóes da linguagem oral no conto de Ribeiro revela que as sutilezas linguísticas podem tornar o texto mais complexo e menos acessível a aprendizes de L2 e a muitos leitores de L1. Ao examinarmos Cerimônia do chá, optamos por discutir alguns aspectos do processo da leitura, tais como o compartilhamento (ou não) de mundos diversos e noções sobre relações de classe e poder, aspectos introduzidos na fala das personagens. Em torno desses pontos, tecemos comentários pertinentes à leitura em si, ao envolvimento conversacional e ao lugar de cada personagem no mundo imaginário e real. Desenvolvemos algumas considerações analíticas sobre o processo da leitura e da pragmática e sobre a estrutura do texto em questão, o qual se constrói através da simulação de um diálogo. Para proceder a este estudo, tomaremos emprestado aspectos tanto da análise da conversação e de teorias de apreensão da leitura como da análise da narrativa oral.

\section{COMPREENDER UM TEXTO OU COMPARTILHAR UNIVERSOS}

Inicialmente, examinaremos algumas características da leitura-um processo complexo, envolvendo operações mentais relacionadas, como extrair imediatamente a informação linguística através das palavras de um texto, integrar informações contidas nas sentenças e parágrafos e sintetizar informação nova, a qual interage com o conhecimento prévio do leitor (KODA, 2007). O conhecimento das palavras é um fator decisivo para a compreensão de um texto. 
De fato, para uma leitura ser bem sucedida, cerca de $98 \%$ das palavras devem ser conhecidas, de acordo com Carver (1994, 2000) e Hu e Nation (2000), a fim de que se possa integrar o conhecimento lexical ao sintático e estrutural e abstrair-se a informação do texto. Isto envolve habilidades de identificar, analisar, manipular, abstrair, inferir e internalizar estruturas implícitas (KODA, 2007), capacidades que os leitores, em geral, possuem, para a compreensão de um texto.

Entretanto, o conhecimento lexical ou das estruturas sintáticas de como uma língua funciona (ou estrutura organizacional) e a habilidade de sintetizar ideias podem não ser suficientes para a compreensão. Este é o caso, por exemplo, quando há outros elementos do discurso que estão embutidos no texto e não são perceptíveis a um leitor desatento, ou que não compartilhe as mesmas experiências ou o mesmo conhecimento.

Sabe-se que o objetivo central de uma leitura é alcançado quando o leitor consegue integrar a informação de um texto ao seu conhecimento prévio. É imprescindível, portanto, que o leitor tenha não só o conhecimento linguístico, mas também do mundo relacionado ao texto, um desafio que se dá não só a nível de L2 como também de L1. O grau de experiência com esses aspectos internos de uma língua pode diretamente influenciar a compreensão de um texto, porque o leitor o vê de forma multidimensional (KODA, 2007), ou seja, partindo do significado de um vocábulo para seu conhecimento pragmático ou, às vezes, inferindo, devido ao seu conhecimento de mundo compartilhado.

Alguns estudos demonstram que a informação internalizada em L1 não é facilmente suprimida, podendo ser automaticamente ativada durante a leitura em L2 (JIANG, 2002; TAN et al., 2003) ou que a competência em L2 depende da competência em L1 (CUMMINS, 1991; HU \& NATION, 2000). Estudos dessa natureza, porém, não dão conta das habilidades que são ou não transferidas para L2. Em resumo, a leitura, tanto em L1 como em L2, envolve muitos aspectos inerentes relacionados não só ao conhecimento linguístico, mas também a outras experiências que permitem abstrair significados linguísticos e pragmáticos.

Como o texto de Ribeiro possui características conversacionais, mencionaremos também aspectos da interação conversacional observados por Gumperz (1982) e Tannen (1998). Embora Gumperz trabalhe com estratégias do discurso falado, consideramos que muitos pontos aplicados à analise do texto conversacional por ele analisados se aplicam ao texto escrito em questão. Para Gumperz (1982), o conhecimento gramatical e lexical são apenas dois 
fatores que atuam durante o processo de interpretação e o conhecimento pessoal, suposiçôes socioculturais e valores sociais também têm um papel importante no processo conversacional. Falar com alguém, participar de uma conversa, é interagir, e isto implica compartilhar ideias, regras linguísticas e sociais. Gumperz afirma que os participantes de uma conversa fazem uso do conhecimento de mundo que possuem para a compreenderem.

Ampliando o conceito de interagir e compartilhar, Lysardo-Dias (2007, p. 209) afirma que a linguagem é

"caracterizada como processo histórico-cultural fundado no intercondicionamento entre o que é da ordem do individual e o que é da ordem do coletivo, entre o que é linguístico e o que é dado como extralinguístico, entre o já sabido e o que é construído no aqui-e-agora da enunciação."

Assim, tanto Gumperz como Lysardo-Dias veem uma conversa como um processo em que nada é isolado. A interação depende de conhecimentos linguísticos e de mundo, do que já passou e se faz refletir no contexto presente. Nesse sentido, nosso estudo procura aproximar a linguagem e as práticas culturais que existem em um texto, observando a natureza sociocultural do discurso e os múltiplos usos linguísticos (LYSARDO-DIAS, 2007). Sendo a língua um fato social, as "práticas verbais não podem ser desvinculadas das práticas coletivas das quais fazem parte, uma vez que há uma interdependência entre o indivíduo e a vida em comunidade." (LYSARDO-DIAS, 2007, p. 210).

Os pontos considerados nos parágrafos anteriores nos levam ao desafio de usar um texto literário como objeto para análise do texto ou do discurso, ou seja, "refletir sobre o que está em um enunciado" (H. H. DA COSTA, 2007, p. 163). A proposta é que, ao contrário do que comumente se diz, que "as palavras e os enunciados existem para traduzirem ou refletirem a realidade", as palavras dão "sentido às coisas, aos acontecimentos, ao mundo, ao universo, à vida, aos próprios sujeitos" (H. H. DA COSTA, 2007, p. 163). Conferir ao texto literário o formato de um enunciado linguístico e discursivo, requer que se passe da abordagem literária para o estudo da linguagem. Costa afirma, "quando se diz ou se escreve alguma coisa, o que, imperativamente, não foi dito ou escrito acaba aparecendo por si próprio" nas palavras e enunciados, (2007. p. 165-166), marcando "seus espaços sócio-históricos e ideológicos" ou, como diz 
Foucault (2002), analisar o discurso é fazer com que desapareçam e reapareçam as contradições que existem no discurso.

Temos que considerar também o fato de que o texto literário expressa relações entre o autor e o leitor, suas palavras e seus mundos (MEY, 2001), tornando-se objeto da pragmática. O texto literário e o texto oral envolvem processos de colaboração para que haja entendimento. Trata-se de uma relação de cumplicidade entre o sujeito-escritor e o leitor por ele imaginado. Assim, o escritor "fabrica uma certa imagem do leitor", à medida que produz um mundo e suas características, evocando uma "realidade" ficcional (CHARADEAU, 1983: 163-164). Neste simulacro, a voz do eu-enunciador propõe um relato que recria uma realidade em que o leitor é convidado a "consumir".

Para ser compreendido, o enunciado precisa ser interpretado pelo leitor, de acordo com o conhecimento de mundo que ele tem e que transparece na sua leitura. Mey refere-se a esse processo de recriação ou inovação, por parte do leitor ou leitora, como um "processo dialético". O autor depende do leitor como um pressuposto para seu trabalho, tanto quanto o leitor depende do autor para que este o oriente para entrar no mundo ou nos mundos criados pelo autor (MEY, 2001, p. 788). Um texto deve proporcionar liberdade para que o leitor entenda, colabore e recrie universos dentro do seu próprio universo (MEY, 2000).

O que acontece quando um texto é oferecido a um leitor que não compartilha das experiências de mundo pressupostas pelo autor para o entendimento do seu texto? Que mecanismos são usados para situar o texto no tempo, espaço e discurso usados pelo autor? Como entender ou recriar o texto? Em Cerimônia do chá, as personagens recontam as histórias através dos turnos de fala, em um texto que recria uma conversa. As personagens falam de objetos e situações sem referências ou explicações. Na tentativa de compreender o texto, o leitor, em contrapartida, esclarece para si mesmo suas percepções, atribui significados valendo-se de elementos que compartilha, criando o contexto no momento que imagina mundos por meio de seu conhecimento. Exemplificando, o leitor terá que apreender o que está incluído nas declaraçōes soltas, quando Luíza, uma das personagens do conto, acompanhante da patroa, responde: "Cuidei de muito menino. Quero mais não" (L10). Como não há referência explícita sobre Luíza, o leitor poderá inferir que Luíza já tenha sido babá ou que tenha tido vários filhos, possivelmente já criados. Além disso, a fala de Luíza nos remete a uma variante regional linguística do Nordeste do Brasil, com a 
qual nem todos os leitores podem estar familiarizados. O leitor passa, então, a se perguntar sobre Luíza e a criar o seu mundo.

A importância da história contada pelas duas mulheres apresenta uma dificuldade em especial, porque o texto é um diálogo com 171 breves trocas de fala entre duas mulheres, sem uma voz narradora que se dirija ao leitor e, explicitamente, esclareça e situe, em algum momento, as personagens no tempo ou espaço, ou que fale das suas emoções, dos seus passados e vivências. $\mathrm{O}$ narrador está presente pela ausência e assim organiza o texto. A conversa entre as duas mulheres tem um duplo papel: o de apresentar o enunciado narrativo e de apontar para a distância social, de poder e hierarquia entre elas. Todavia, a marcação temporal, hierárquica e de poder acontece através das contradições que as personagens exibem, ao mesmo tempo, encontro, desencontro e uma cumplicidade contraditória entre elas, conforme discutido a seguir.

\section{CERIMÔNIA DO CHÁ: O CONTO}

Cerimônia do chá aparece, inicialmente, em Boa Companhia, uma coletânea de contos com diversos autores, publicada pela Cia das Letras, em 2003. Em 2009, a Editora 7 Letras publica Quarteto de Cristal. O livro, cujos contos são todos de autoria de Maria Telles Ribeiro, inclui Cerimônia do chá. O texto é construído através do diálogo de duas personagens e apresenta uma série de atividades e passos que relacionam a experiência de tomar chá com amigas, formalmente, com uma espécie de ritual. O texto progride com falas, ou turnos, das duas personagens, fazendo referências a elementos que podem tornar a apreensão do universo criado mais complexa e desafiadora.

A narrativa de Cerimônia do chá inicia-se com um diálogo, no qual a patroa dá instruções à empregada para a preparação de um chá para suas amigas. À medida que as duas interagem, ficam claras as diferenças sociais entre si, que são marcadas também pela diferença no conhecimento que têm sobre o chá como cerimônia. Para a empregada, beber chá é uma necessidade, e há chás diferentes para problemas de saúde diferentes. Para a patroa, beber chá é um processo, cuja elegância é medida através dos variados objetos e produtos dispostos na mesa, o que compreende desde o tipo de chá até as xícaras e a maneira de dispô-las na mesa. Baseando-se nessas diferenças, perpassadas no diálogo, o texto propõe uma discussão de relações de classe, mas também de poder-submissão através da 
interação entre patrão-empregado. Essas relações são construídas através da linguagem, em um diálogo que marca as diferenças no conhecimento, no modo de expressão e nas subsequentes realidades de cada personagem.

A estratégia de contar a história através do diálogo das personagens também favorece a criação de sentido com uma participação mais intensa da audiência, no caso, o leitor/a leitora. Isso é verdadeiro também nas narrativas orais, que aparecem frequentemente em conversas do dia a dia, nas quais a inclusão da fala de outrem permite à audiência "ver com os próprios olhos" aquilo que, de outro modo, descrever-se-ia. Essa estratégia, conforme apontado por Tannen (1998), também serve ao propósito de criar envolvimento, pois recria, como no teatro, a relação entre audiência e personagens, permitindo-lhe também chegar a suas próprias conclusóes acerca do que se discute.

No entanto, é esse aspecto do conto que pode causar dificuldades a leitores não nativos de português, ou mais desatentos, talvez menos informados. O envolvimento é também consequência do entendimento das relações que são transmitidas através da linguagem empregada e, não se compreendendo a rápida transição nos turnos de falas curtas entre as duas personagens, torna-se mais difícil apreender quaisquer outras noções expressas no texto, tais como as já acima mencionadas, de classe e de poder, além de capturar a essência de certas expressões linguísticas, escolhas gramaticais e sintáticas que revelam regionalismos da variante portuguesa brasileira. Uma vez que a compreensão de qualquer forma verbal de expressão é precedida pelo conhecimento de mundo dos interlocutores, a inabilidade de reconhecer os elementos referenciados no diálogo das duas personagens constitui um desafio para aqueles que não conhecem a fundo a língua e suas variações, não compartilhando do mesmo universo.

\section{UNIVERSOS (NÃO)COMPARTILHADOS}

De acordo com Gumperz, o "conhecimento linguístico e sociocultural precisa ser compartilhado para que o envolvimento conversacional possa ser mantido" (1982, p. 2-3). No texto Cerimônia do chá, observamos que as duas personagens, embora tão próximas, não compartilham do mesmo universo, conforme demonstrado quando a patroa se dirige a Luíza e pede-lhe que "Apanhe o samovar" (L13). Luíza apenas pergunta "Samovar?" demonstrando desconhecimento do termo, o que é ignorado pela patroa. Isso também ocorre 
na linha 61, quando a patroa diz, "Tem um filme antigo tão bonito! A casa de chá do luar de agosto. Marlon Brando de quimono, as gueixas", ao que Luíza nada responde, como se vê na fala marcada apenas com reticências "..." (L62). Em outro ponto do diálogo, ao ouvir a patroa mencionar "queijos estrangeiros" (L109), Luíza adianta: "os russos, os ingleses" (L110), numa clara referência a turnos anteriores, quando a patroa fala "Dos czares da Rússia" (L15) e "Chá inglês, do bom" (L33). Luíza não tem ideia de que os queijos finos aos quais a patroa se refere sejam "Os franceses. O Brie, o Allouette..." (L111). Nos três pontos mencionados, não há envolvimento conversacional nos moldes mencionados por Gumperz, porque as duas fazem parte de mundos e experiências diferentes. Isso também se observa nas falas de Luíza "De olhar, só de olhar" (L70). A patroa parece se questionar sobre o que Luíza estaria falando e, como resposta, temos o turno da patroa com três pontos de interrogação "???” (L71). Entre as linhas 144 a 152, as duas falam de situações distintas: a patroa menciona os últimos detalhes do chá e Luíza conclui que é muito mais fácil fazer 'um peru de Natal enorme' do que preparar o tal chá da tarde com tanta etiqueta e finesse. Em 160, Luíza volta a mencionar o peru e a farofa ao dizer "O negócio é socar", quando a patroa fala sobre as rosas, "Sempre ímpar o número de rosas. Aprenda." (L159).

A noção de compartilhar universos ou o conhecimento de mundo do leitor como um aspecto relevante para a compreensão de um texto, conforme já visto, pode refletir-se tanto no vocabulário quanto na estrutura de um texto, nas informaçóes culturais subliminares, na mensagem contida no texto, nas alusões e menções para que o leitor possa integrar o texto ao seu conhecimento de mundo e compreendê-lo. Verificamos que o conto trabalhado referia-se a elementos inacessíveis a alguns leitores para que estes pudessem processar o texto como atividade de compreensão. Quando Luíza responde "Quero mais não" (L10)—uma frase negativa após uma afirmativa—há informaçôes que merecem explicações de caráter linguístico-regional sobre variantes do português brasileiro. Em outro ponto do diálogo, Luíza declara, "Tomar, tomei muito, em pequena. Chá de cadeira também. Só falta o de sumiço." (L44). As expressões "chá de cadeira” e "chá de sumiço", se não fazem parte do universo do leitor, tornam-se suscetíveis a se deslocarem discursivamente para outro ponto. O contexto imediato não dá conta do percurso dos enunciados, e informações adicionais que possam levar os leitores a compartilhar mundos fazem-se necessárias. Isso se passa em vários outros pontos do diálogo, como a cantilena final de Luíza, a qual era desconhecida pela patroa. 
Compartilhar universos é um aspecto de importância crucial em uma conversa, podendo-se inferir, negociar o significado das falas, e viabilizar a cooperação conversacional para que haja compreensão e consequente interação e comunicação. Para o leitor que se depara com um texto sem sincronia entre as personagens, como ocorre na maioria das falas em Cerimônia do chá, a compreensão poderá ser grandemente afetada se ele não compartilha dos mesmos universos socioculturais contidos no texto em si. Uma vez que o conhecimento sociocultural, lexical e regional é estabelecido entre o leitor e o texto, o leitor processará as falas, contextualizando os sinais linguísticos associados às diferentes convenções e aos (des)conhecimentos das duas personagens e finalmente compreenderá o texto. O leitor "aplicará o seu conhecimento de mundo à interpretação” do texto (GUMPERZ, 1982, p.154).

\section{RELAÇÕES DE CLASSE E PODER}

O texto de Cerimônia do chá, por sua estrutura, permite-nos a discussão de vários aspectos relativos ao contexto social dos personagens que são constituídos através do diálogo entre elas. Dentre os aspectos em questão, destacaremos:

1) as relaçôes de classe entre as personagens, tais como expressas tanto no conteúdo referencial do texto como na linguagem atribuída a cada personagem, respectivamente;

2) a relação de poder e solidariedade verificada através da interação recriada entre patroa e empregada, que discutem a melhor forma de servir um chá oferecido pela primeira às suas amigas.

Vejamos como essas relações são entabuladas no decorrer do conto.

A primeira linha do diálogo entre a patroa e a empregada neste conto é uma pergunta, também um diretivo da primeira, e que já nos indica como as duas se relacionam: "Quem vai servir, se a Penha não vem hoje?" (L1). Com essa pergunta, tem início a interação entre Luíza e a patroa, na qual a última assume a posição hierárquica mais alta, o que é corroborado pelo tipo de função comunicativa e atos de fala que executa durante o diálogo. Por exemplo, algumas linhas depois que Luíza propõe desmarcar o chá e revela não ter experiência 
com este tipo de serviço, a patroa oferece mais um índice que contribui para caracterizar a sua posição em "Luíza, você vai servir o chá" (L5). É interessante observar também que, nesse caso, embora a empregada tenha nome e a nós seja dado conhecê-lo, isso não ocorre com a patroa, que só passamos a conhecer pelos atos de fala e pelas expressôes tipicamente atribuíveis a um indivíduo que ocupe uma posição de autoridade em relação a outro.

O universo referencial no texto é um outro recurso através do qual a autora nos permite conhecer a discrepância entre as duas personagens no que tange às respectivas posiçôes sociais que ocupam. Veja-se, como exemplo, a sequência em que a patroa dá ordens à empregada sobre como servir o chá, ao pedir-lhe que "abra a cristaleira" (L13) e "apanhe o samovar" (L13) "dos czares da Rússia” (L15). A posição social relativamente baixa em relação à da patroa é também marcada pelas respostas de Luíza, as quais parecem associar os referentes a uma realidade distinta da de sua patroa. Quando a patroa pergunta a Luíza se ela nunca havia tomado chá, a sua resposta em (L44)) realça as suas diferenças. Desta forma, a classe social de cada uma é veiculada à experiência de tomar chá: se, para a patroa, o chá é uma cerimônia a ser observada nos seus mínimos detalhes, "uma cerimônia com ritual e tudo" (L51), e para a qual se requer um samovar brilhoso e limpo, para Luíza, tomar chá "é para todos: bocós, coiós, donzelas aflitas, viúvas esfogueadas, capiauzinho de mãe sem leite; magrelos, manipansos" (L52). A distinção entre a classe social das duas, portanto, dá-se tanto pelo conteúdo referencial, como pela expressão verbal propriamente dita.

À medida que Luíza e a patroa trocam informaçōes, fica clara a diferença não só entre o que a primeira desconhece e que lhe é praticamente ensinado pela segunda, mas também entre $o$ tipo de conhecimento que as duas têm. Não se trata, então, de a patroa saber e ensinar Luíza, mas que o tipo de conhecimento de cada uma marca um lugar específico na escala social.

Procedamos a mais um exemplo: ao apontar as xícaras a serem usadas para servirem-se os diferentes tipos de chá, Luíza observa uma "que tem uma asinha colada", ao que a patroa responde "Famoso, o chá verde japonês" (L59). A reação de Luíza é transmitida em uma relação de tipos da bebida (chás) preparados com base no "capim", em clara contraposição à sofisticação e conhecimento da patroa ("chá verde") e marcando o tipo de conhecimento e experiência de Luíza. A comparação implícita é um recurso amplamente empregado no conto e contribui para a caracterização das personagens. Como em uma peça de teatro, 
assistirmos ao diálogo entabulado entre patroa e empregada permite-nos chegar à nossa própria conclusão quanto à natureza da relação entre as duas.

A ausência de uma voz que comente as intenções dos personagens, mas que se faz presente pela ausência, expóe o leitor à tarefa de apreender as alusões feitas por meio do diálogo. Ora, se um aprendiz de português como L2 encontra-se no estágio em que a apreensão de novo vocabulário ainda é uma tarefa essencial, o entendimento de noções mais complexas e que, inclusive, relaciona-se a relações culturais (i.e., usam-se chás de ervas para sanar males físicos e psicológicos, a nomenclatura popular das mazelas citadas), pode ficar potencialmente comprometido.

A sequência de linhas no diálogo entre Luíza e patroa reforça a noção de que há dois indivíduos, aparentemente trocando enunciados, mas que, de fato, mais parecem estar monologando. Enquanto a patroa continua a digressão sobre o chá verde, ou o propósito maior de beber chá em uma cerimônia para, entre outras possibilidades, "elevar a mente", Luíza discorre sobre os "poderes" mais práticos da bebida e sua popularmente confirmada eficácia para sarar males de saúde. Na verdade, Luíza revela um entendimento sobre o chá como remédio, tal como prescrito popularmente em certas regiōes (e épocas) no Brasil, exemplificado em L66, "Para tremedeiras, soluços, desmaios, calores súbitos, suores gelados, suores quentes, Para aquecer mulher fria. Para esfriar mulher quente. Para homem...”. A patroa, em contrapartida, revela um entendimento e experiência de mundo que se contrastam com os de Luíza, uma vez que suas referências são, quase sempre, a tradições reconhecidamente estrangeiras.

Quando as falas entre as duas personagens se encontram mais uma vez (e tem-se a impressão de que falam de uma para a outra e não para si mesmas), a patroa questiona o tipo de chá que Luíza menciona "de olhar, só de olhar" (L70). Para a patroa, trata-se de "crendices" (L73), um termo que caracteriza a referência da empregada como de origem "inculta", "não sofisticada”, sem mérito para ser levada a sério. Esta linha, então, reforça a noção de que as falas das duas personagens recriam o universo socialmente estratificado, no qual a patroa é detentora da informação de mais valor e ocupa a posição mais alta na esfera de poder relativamente à empregada, ao passo que esta última se orienta por "crendices". Um outro aspecto a reforçar esta interpretação é o tipo de atos de falas de cada personagem. Nota-se que, até a conclusão da narrativa, a patroa emite diretivos, exibe impaciência, urge e aconselha, ao passo que Luíza responde e supre factoides relativos à cultura popular da qual se mostra conhecedora. 
Vejamos a sequência final de interação entre as duas personagens, à medida que a patroa urge Luíza a: 1) ser cuidadosa no manuseio dos pratos; 2) lembrar-se dos diversos apetrechos para pôr a mesa; 3) vestir-se apropriadamente para a ocasião. Nestas linhas, observamos em várias trocas de fala o uso do imperativo na transmissão dos diretivos exclusivamente nos turnos da patroa, por exemplo em "Cuidado" (L81), "Aproveita e separa a toalha" (L83). Luíza responde com perguntas (por vezes não endereçadas pela patroa) e com declarações que se relacionam apenas ao tema geral da conversa e que refletem uma compreensão apenas superficial do referente na menção da patroa. Entre as trocas nas linhas 13 a 20 , tem-se a impressão de que as duas falam para si próprias. A primeira linha abaixo é da patroa e a sequência é sempre de Luíza. Note-se a troca rápida de enunciados e o fato de as perguntas de Luíza ficarem sem respostas no texto de Ribeiro. Abra a cristaleira. Apanhe o samovar. Samovar? Dos czares da Rússia. Dos tempos do meu avô. Seu avô era russo?

(21) Bota em cima da mesa. $\mathrm{O}$ açucareiro ainda está cheio. Passe uma flanela, dê um brilho. Não sei como não deu formiga. O bule grande é o da água quente.

(26) Bule-grande água-quente

(29) __ Bem fininhas, as tirinhas.

(30) __ Chazinho de bonecas.

Luíza quebra a sequência de repetiçôes (L30), mas a patroa ignora sua declaração também afirmando, "A lata verde é do chá”. Somente quando Luíza 
pergunta se não é a do saquinho, a patroa responde, mas com veemência, o que também contribui para fortalecer sua posição de autoridade (DAVIES \& HARRÉ, 1990), como patroa. Essa posição de autoridade sobre Luíza é reforçada ao longo da sequência. Note-se abaixo que, quando, por fim, as duas personagens parecem trocar informaçōes e dialogar, tem-se Luíza fazendo perguntas e a patroa repreendendo-a com autoridade. Não-vou-saber-fazer-não-senhora. É muito simples! A água fervendo para a infusão. Isso o que é?

O chá no bule grande. A água por cima.

O leite frio e ramplan!

Mas só na hora.

Que hora?

Esse é que é o seu mal, Luíza. Não presta atenção. A professora já dizia......

A declaração um tanto formulada em L34 é respondida com instruções da patroa. Entretanto, observa-se que, quando Luíza afirma não saber o que é infusão, isso também não é explicado. A patroa continua uma sequência que indica sua preocupação com a preparação do chá, apenas. Mais uma vez, quando fica claro que Luíza não entende, segue-se uma declaração da patroa repreendendo-a, em (L41), o que também contribui para reforçar sua posição de autoridade. Vê-se que a patroa é a que detém o poder para emitir diretivos e repreensões. Mais exemplos dessa relação de poder, tal como vista pela emissão de enunciados diretivos encontram-se em (L89), (L99), (L113), (L115), (L133), (L139), (L149), (L151), (L161), (L163), (L165) em que a patroa provê instruçōes para a empregada através do uso do verbos no imperativo.

Percebe-se uma regularidade na forma como a posição da patroa é afirmada, e notamos um padrão semelhante na elaboração das perguntas da empregada. Veja-se, a exemplo, que a construção da sua posição como submissa em relação à da patroa é constantemente afirmada pelo formato das suas respostas. Assim, enquanto lemos da patroa instruçôes e diretivos, "ouvimos" de Luíza uma série de referências à cultura popular, como quando ela parece lembrar-se de uma cantiga ou ditado popular inserindo-os após um 
dos diretivos da patroa em (L166) e (L170). A linha conclusiva do diálogo e do conto corrobora esta relação travada ao longo da narrativa, quando a patroa conclui exortando Luíza, "Vamos, vamos", (L171).

\section{CONCLUSÃO}

Enquanto se devota muita atenção ao estudo da oralidade através da coleta e análise de conversas informais, através de entrevistas de pesquisa, este estudo objetivou a observação da recriação interacional na escrita. Uma análise dessa natureza revela-se útil por várias razões, entre as quais, a percepção de que um texto como Cerimônia do chá pode fornecer importantes elementos para se compreender melhor o próprio funcionamento da fala. Por tentar recriar um diálogo, a narração deste conto faz-nos lançar mão do nosso arcabouço de "ferramentas" empregadas para fazer sentido da linguagem com que nos deparamos. Afinal, os mecanismos pelos quais compreendemos o mundo partilham de uma certa regularidade. A compreensão de qualquer texto é possível, em parte, por termos conhecimento de fundo, anterior sobre aquilo com que nos deparamos. Sendo assim, conforme afirma Bakhtin (1986), o discurso atual retoma o anterior, relacionando-se com ele. Não existem discursos absolutamente "novos" neste sentido e todo texto é, de certo modo, um intertexto (BECKER, 2000).

Essa interpretação lança luz sobre importantes questōes para aqueles que se dedicam ao ensino de línguas. Como a experiência empírica e prática com a leitura de Cerimônia do chá em aulas de Português como língua estrangeira tem nos revelado, "entender" um texto vai além da compreensão lexical, pois a apreensão do universo (re)criado através de uma narrativa só pode ser dar em um espaço de intersecção de conhecimento. Autor/escritor e leitor/audiência compartilham papéis no âmbito das suas respectivas relações. Se precisamos contar com uma certa capacidade de antecipação por parte da nossa audiência ao tratarmos de um dado assunto, isso também se verificará ao lidarmos com o texto escrito. Desta forma, a elaboração de atividades de compreensão textual beneficiar-se-ia de uma visão mais crítica da necessidade de compreendermos um espaço, uma cultura, antes de podermos compreender sua linguagem.

Evidentemente, tal asserção precisa ir além do âmbito de uma análise qualitativa para se afirmar, mas julgamos ter dado aqui uma importante 
contribuição nesta direção. Um passo futuro seria a elaboração de um estudo de variáveis controladas, com um componente quantitativo, com o objetivo de estabelecer de modo mais claro como, e até que ponto, dá-se a compreensão de um texto como Cerimônia do chá.

\section{NOTAS}

${ }^{1} \mathrm{O}$ texto completo encontra-se no final do trabalho, com permissão da Editora 7 Letras.

${ }^{2}$ Segunda língua (L2) e língua estrangeira (LE) significam, neste trabalho, a aprendizagem de uma língua que não a nativa, sem outras implicações quanto ao número de línguas que uma pessoa fala, ou ao local onde a língua está sendo aprendida.

\section{REFERÊNCIAS}

BAKHTIN, M. Estética da criação verbal. São Paulo: Martins Fontes, 1986. 421p.

BECKER, A. L. Beyond translation: Essays toward a Modern Philology. Ann Harbor:The University of Michigan Press. 2000 (first edition 1995), 438p.

CARVER, R. P. Percentage on unknown vocabular words in text as a function of relative difficulty of the text: Inplications for instruction. Journal of Reading Behavior, 26, 413-437, 1994.

----. The cause of high and low reading achievement. Mahwah, NJ: Erlbaum, 2000.460p. CHARAUDEAU, P. Langage et discours. Paris: Hachette. 1983. 174p.

COSTA, Hermes Honório da. E aquelas mãos que confessam... In: FERNANDES, Cleudemar Alves \& DOS SANTOS, João Bôsco Cabral (Org.). Percursos da análise do discurso no Brasil. São Carlos, SP: Editora Claraluz, p. 163-184. 2007. $214 \mathrm{p}$.

CUMMINS, J. Interdependence of first- and second-language proficiency in bilingual children. In: BIALYSTOK, E. (Ed.), Language processing in bilingual children. New York: Cambridge University Press. p. 70-89. 1991. 236p.

DAVIES, B. \& HARRÉ, R. Positioning: The Discursive Production of Selves. Journal for the Theory of Social Behaviour 20, p. 43-63. 1990.

FOUCAULT, Michel. A arqueologia do saber. Rio de Janeiro: Forense. 2002. 264p. 
-----. A arqueologia do saber. (1995a ). Tradução de Luiz Felipe Baeta Neves. Rio de Janeiro: Forense Universitária. 2002.

GUMPERZ, John J. Discourse Strategies. Cambridge: Cambridge University Press. 1982. 225p.

HU, M. \& NATION, I. S. Unknown vocabular density and reading comprehension. Reading in a Foreign Language, 13, 403-430, 2000.

JIANG, N. Form-meaning mapping in vocabulary acquisition in a second language. Studies in Second Language Acquisition, 24, p. 617-638. 2002.

KODA, Keiko. Reading and language learning: Crosslinguistics constraints on second language reading development. Language Learning. 57: Suppl. 1, June, p.1-44. 2007.

-----. Insights into second language reading. New York: Cambridge University Press. 2005. 320p.

----. 2000. Cross-linguistic variations in L2 morphological awareness. Applied Psycholinguistics, 21, p. 297-320.

LYSARDO-DIAS, Dylia. As ferramentas teóricas da análise do discurso no ensino de língua. In: FERNANDES, Cleudemar Alves \& DOS SANTOS, João Bôsco

Cabral (Org.). Percursos da análise do discurso no Brasil. São Carlos, SP:

Editora Claraluz, p. 207-214. 2007. 214 p.

MEY, L. Jacob. Literary pragmatics. In: SCHIFFRIN, Deborah, TANNEN, Deborah

Tannen, \& HAMILTON, Heidi E.. The Handbook of Discouse Analysis. Malde,

MA: Blackwell, p.787-797. 2001. 872p.

----. When Voices Clash: A Study in Literary Pragmatics. Berlin and New York: Mouton de Gruyter. (2000)1999. 459p.

-----. Pragmatic problems in literary texts. In: MILLAR, Sharon \& MEY, Jacob L. (Ed.). Form and Function in Language. Odense: Odense University Press. (Rask Suppl. v. 21, p. 151-170, 1995.

RIBEIRO, Maria Telles. Cerimônia do chá. In VARIOS AUTORES, Boa Companhia. Contos. Rio de Janeiro: Cia das Letras, 2003.128p.

TAN, L. H., SPINKS, J. A., FENG, C. M., SIOK, W. T., PERFETTI, C. A., XIONG, J., FOX, P. T. \& GAO, J. H. Neural systems of second language reading are shaped by native language. Human Brain Mapping, 18, p.158-166, 2003. 
TANNEN, Deborah. Involvement in discourse. Talking Voices. Cambridge: Cambridge University Press, p. 25-47, 1998. 240p.

Texto completo, com permissão da Editora 7 Letras

\section{Cerimônia do chá, de Maria Ribeiro Telles}

(1) _ Quem vai servir o chá, se a Penha não vem hoje?

(2) __ Não pode desmarcar?

(3) ___ Em cima da hora? Imagine! Há mais de dez anos que nos reunimos 'as quintas-feiras.

(4) Hoje é o seu dia.

(5) __ Luíza, você vai servir o chá.

(6) ___ Eu, não. Só sei desses chazinhos que a senhora toma ‘a noite.

(7) __ Nunca serviu ’a francesa?

(8) __ Nem ’a brasileira.

(9) ___ Fazia o quê, antes de ser acompanhante?

(10) __ Cuidei de muito menino. Quero mais não.

(11) __ Mas é só preparar o carrinho. Já viu isso tantas vezes!

(12) __ Nunca prestei atenção.

(13) __ Abra a cristaleira. Apanhe o samovar.

(14) _ Samovar?

(15) ___ Dos czares da Rússia. Dos tempos do meu avô.

(16) __ Seu avô era russo?

(17) _ Bota em cima da mesa.

(18) _ _ O açucareiro ainda está cheio.

(19) __ Passe uma flanela, dê um brilho.

(20) __ Não sei como não deu formiga.

(21) __ O bule grande é o da água quente.

(22) __ Bule-grande água-quente.

(23) __ O bule pequeno, do leite. Leite frio.

(24) B Bule-pequeno-leite-frio.

(25) __ O pirezinho do limão.

(26) __ Pirezinho-do-limão.

(27) __ Em tirinhas. Sem casca. 
(28) Sem casca.

(29) ___ Bem fininhas, as tirinhas.

(30) __ Chazinho de bonecas.

(31) ___ A lata verde é do chá.

(32) ___ Não é o do saquinho?

(33) ___ Que saquinho! Chá inglês, do bom.

(34) __ Não-vou-saber-fazer-não-senhora.

(35) ___ É muito simples! A água fervendo para a infusão.

(36) ___ Isso o que é?

(37) __ O chá no bule grande, a água por cima.

(38) __ O leite frio e ramplan!

(39) ___ Mas só na hora.

(40) __ Que hora?

(41) ___ Esse é que é o seu mal, Luíza. Não presta atenção.

(42) ___ A professora já dizia...

(43) ___ Somos cinco. A medida: uma colher por pessoa. Até parece que você nunca tomou um chá!

(44) _ Tomar, tomei muito, em pequena. Chá de cadeira também. Só falta o chá de sumiço.

(45) ___ O chá é a bebida mais antiga do mundo. Vem da China.

(46) ___ Tudo não veio da África?

(47) __ Da África é o homem. Estamos falando de chá. Aproveita e desce a louça. A da Companhia das Índias.

(48) ___ Chá das Índias?

(49) ___ A porcelana azul.

(51) ___ Não foi na China. Foi na Índia. Países muito antigos, Luíza. No Japão é uma cerimônia com etiqueta ritual e tudo. Aqui é pra todos: bocós, coiós, donzelas aflitas, viúvas esfogueadas, capiauzinho de mãe sem leite; magrelos, manipansos.

(53) Mani quê?

(54) __ Gordos.

(55) ___ Cuidado com a louça. Separe cinco de cada.

(56) __ Cada o quê?

(57) _ Cada coisa, Luíza, o que poderia ser? Cinco xícaras.

(58) __ Tem uma asinha colada. 
(59) ___ Famoso, o chá verde japonês.

(60) ___ Aqui só de capim temos vários! $\mathrm{O}$ azul, o amarelo, o melado, o limão, o mimoso. O capim santo, o capim cidreira ...

(61) ____ Tem um filme antigo tão bonito! A casa de chá do luar de agosto. Marlon Brando de quimono, as gueixas.

(62)

(63) ___ Uma arte belíssima, a cerimônia do chá. Quanto maior o prazer de prepará-lo, mais delicioso para quem o tomar.

(64) ___ O meu então vai ser de amargar.

(65) ___ O relaxamento da mente.

(66) __ Também temos. Para tremedeiras, soluços, desmaios, calores súbitos, suores gelados, suores quentes, Para aquecer mulher fria. Para esfriar mulher quente. Para homem...

(67) ___ A ideia é elevar mente ao seu mais alto grau de harmonia.

(68) ___ Então éa a raiz do salgueiro. Não tem nada melhor. Mas essa não é de beber.

(69) __ É de quê?

(70) __ De olhar, só de olhar.

(71) _ ???

(72) ____ Se deixar a raiz à noite num lugar escuro ela deita uns vapores estranhos. Aí é só jogar água benta e fazer o pedido.

(73) ___ Crendices.

(74) ____ Água benta não é bom prá tudo? A senhora mesma não tem no quarto uma piazinha cheia? Então. Verdade! É um segredo que vem de longe De Monteserrate. Do tempo dos mouros.

(75) __ Dos mouros?

(76) __É o que dizem.

(77) ___ E essa raiz é boa prá quê?

(78) ___ Para a pessoa ficar extasiada.

(79) ___ Extasiada de quê?

(80) ___ Do que quiser.

(81) _ Cuidado. O prato grande é do bolo. Já está pronto na forma.

(82) __ Não-sou-boa-de-desenfornar-bolo-não-senhora.

(83) ___ Aproveita e separa a toalha. Primeira gaveta. E os guardanapinhos. 
(86) ___ De papel?

(87) ___ Os bordados iguais à toalha.

(88) ___ Estão manchados.

(89) ___ Passe uma aguinha, seca depressa.

(90) $\ldots$

(91) ___ O uniforme está na terceira gaveta. Ainda bem que a Penha tem seu corpo.

Se for preciso faça uma bainha.

(92) ___ Este meu não serve?

(93) ___ Acompanhante é acompanhante copeira é copeira.

(94) __ Lá isso é.

(95) __ A touquinha está junto.

(96) ___ Vou botar touquinha?

(97) __ Mas claro.

(98) ___ Meu cabelo não segura.

(99) ___ Prega um grampinho. Até que seu cabelo seria bonito se tivesse trato.

(100) ___ Minha mãe dizia...

(101) _ _ LUÍZA!

(102) _???

(103) __ Os canapés! Já ia me esquecendo.

(104) ___ Isso o que é?

(105) ___ Os salgadinhos.

(106) ___ Aqueles biscoitinhos?

(107) _ _ue biscoitinhos? Canapés. O pão está cortado é só passar as pastas.

(108) ___ Pastas? Que pastas?

(109) _ _ O foie gras, o salmão, os queijos. Queijos estrangeiros.

(110) __ Os russos, os ingleses.

(111) __ Os franceses. O Brie, o Allouette, La Vache qui rit.

(112) __ La Vache.

(113) ___ Esmague com o garfo...

(114) __ E é tão tal.

(115) __ Mas antes passe a maionese.

(116) __ Onde?

(117) __ No pão, onde havia de ser?

(118) _ Certo. 
(119) ___ Misturada com creme de leite.

(120) ___ Antes mesmo de quê?

(121) __ Das pastas.

(122) _ A A sim.

(123) __ Pouca.

(124) ___ Pouquíssima. Espera aí: a maionese no pão, o creme de leite na maionese, as pastas ...

(125) __ Não em todas as pastas.

(126) _ _ Não!

(127) __ Na de atum pode.

(128) ___ Esta onde está?

(129) _ Tudo com ovo picado ou azeitona.

(130) ___ Onde?

(131) __ No tomate, na alface. Onde havia de ser?

(132) ___ Por quê? Vai ter salada?

(133) __ Não se esqueça de lavar bem as folhinhas.

(134) _ - . .

(135) ___ Água filtrada com vinagre. Olha a dengue.

(136) __ Brava!

(137) ___ E como sempre tem alguém que pede uma geleia...

(138) __ Será?

(139) __ Bote os potes no carrinho. Embaixo.

(140) ___ Acabou?

(141) __ O resto é de somenos.

(142) __ É de que?

(143) ___ Ah, o mel está no armário da copa.

(144) __ Mais fácil um peru de Natal. Muito mais fácil!

(145) ___ Mel não se bota na geladeira, sabia?

(146) __ Daqueles enormes! Para vinte pessoas.

(147) __ Deixa ver se tem mais alguma coisa....

(148) __ Recheado. Socar tudo lá dentro! Farofa, miúdos, castanhas, nozes, passas.

(149) ___ Ah sim, separe o vestido verde.

(150) _ Bem socado.

(151) ___ Passe bem as pregas. 
(152) ___ O peito e as perninhas pra cima. O forno faz o resto.

(153) ___ As joinhas eu mesma vejo. Basta me botar os bobes. Ah, o sapato gelo. E a bolsinha? Dona de casa não usa bolsinha. É mesmo. Antes que me esqueça, telefone para o florista. Peça rosas amarelas.

(159) _ _uinze. Sempre ímpar o número de rosas. Aprenda.

(160) __ O negócio é socar.

(161) _ C Comece já, por esta sala. Passe o aspirador e um pano nos móveis. (162) __ Bem socado.

(163) __ Retoque o banheiro. Troque o sabonete, as toalhas.

(164) __ É no que dá trabalhar nas casas alheias.

(165) ___ E pelo amor de Deus não vá me tropeçar no tapete com o carrinho. (166) __ Oi dona Luíza Morreu seu José E a dona Maria E o cachorro Bicó.

(167) __ Que cantilena é essa?

(168) ___ É lá da minha terra. O cachorro Bicó é pra gente não ir junto.

(169) ___ Estamos em cima da hora.

(170) ___ E para golão traga Matão ai do pato chião o militão.

(171) ___ Vamos, vamos. 
